\title{
Clinical Reasoning: Rapidly Progressive Thalamic Dementia
}

Angelo Cascio Rizzo, MD, Novella Bonaffini, MD, Raffaele Bove, MD, Mara Gentile, MD, Letizia Maria Cupini, MD, Enrico Cotroneo, MD, and Cesare lani, MD

Neurology ${ }^{\circledR}$ 2021;96:e809-e813. doi:10.1212/WNL.0000000000011161
Correspondence

Dr. Cascio Rizzo

a.casciorizzo@unicampus.it

\section{Section 1}

A 61-year-old White man with hypertension and diabetes presented to the emergency department with a 10-day history of excessive daytime sleepiness, confusion, mental slowing, memory loss, and behavioral changes. He had become apathetic and quieter with loss of initiative and showed reduction of spontaneous speech. No headache, fever, or recent infections were reported. Neurologic examination revealed hypomimia, mild parkinsonism (mild rigidity of the left arm, reduced bilateral arm swing during gait, global mild bradykinesia), confusion with partial disorientation in time and space, and short- and long-term memory impairment. Mini-Mental State Examination Scale score was 15. Cranial nerves, speech, language, motor, sensory, and cerebellar functions and reflexes were normal. Brain CT scan and arterial and venous CT angiography (CTA) were normal. The patient was admitted to our neurologic department for further management.

Complete blood tests revealed only mild thrombocytopenia (platelet count $105 \times 10^{9} / \mathrm{L}$ ); fibrinogen was $645 \mathrm{mg} / \mathrm{dL}$ (normal value 200-400). EEG showed a 9-10 Hz background activity with frequent, medium-voltage, bilateral theta-delta activity prevalent in the frontal regions, suggestive of diffuse encephalopathy. Brain MRI demonstrated bilateral, symmetrical thalamic T2-weighted and fluid-attenuated inversion recovery (FLAIR) hyperintensities (figure, A) with partial involvement of the midbrain (quadrigeminal lamina and periaqueductal gray) (figure, B-D) and T1-weighted hypointensities in the same regions with a subtle, patchy gadolinium enhancement. Neither a significant restriction in diffusion-weighted imaging nor apparent diffusion coefficient reduction was appreciated in the same regions. Magnetic resonance venography excluded deep cerebral venous system thrombosis.

\section{Questions for Consideration:}

1. What is the differential diagnosis for T2-weighted bilateral thalamic hyperintensities?

2. What would be the most appropriate next step in the diagnostic evaluation? 
Figure Brain MRI at Admission and at Follow-Up and Cerebral Angiography Revealing Dural Arteriovenous Fistula

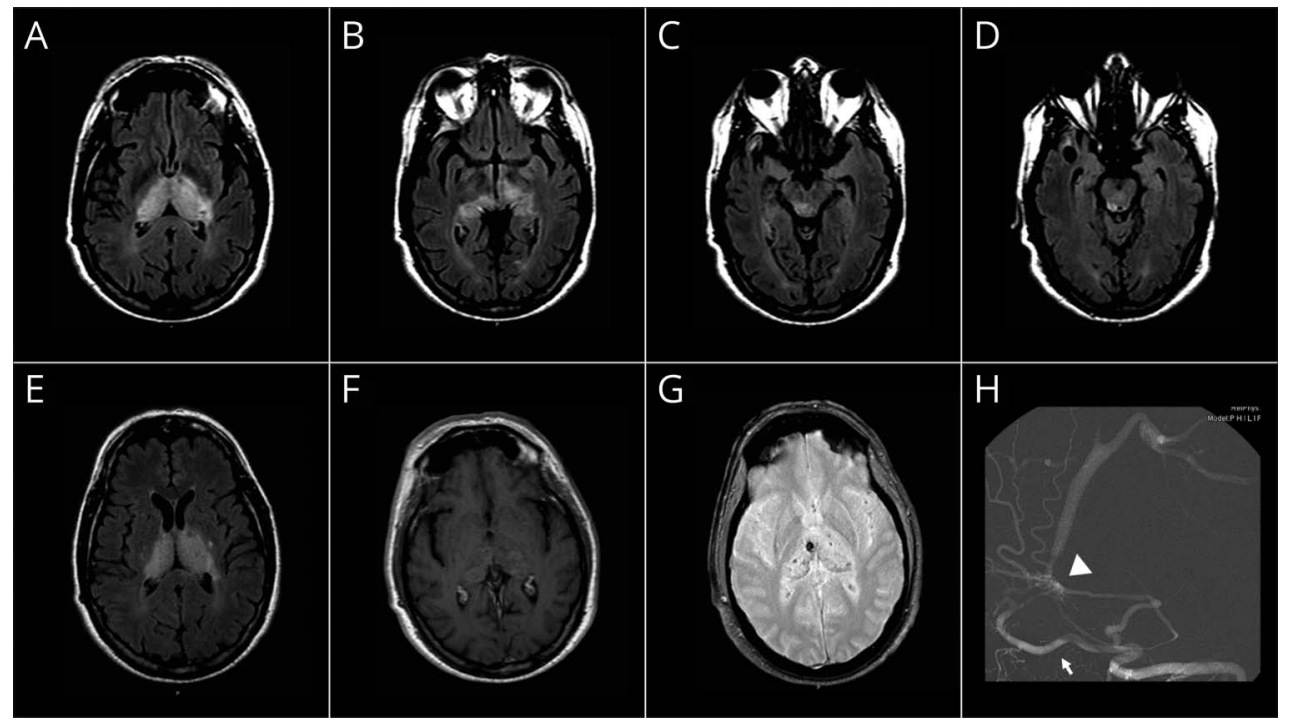

Brain MRI performed at the admission: fluid-attenuated inversion recovery (FLAIR) sequences show bilateral thalamic hyperintensities (A) with partial involvement of the midbrain $(B, C)$ and periaqueductal gray (D). Follow-up brain MRI confirmed bilateral thalamic hyperintensities in FLAIR sequences (E), with patchy gadolinium enhancement (F), and new-onset microhemorrhage in the right thalamus on gradient echo imaging (G). Digital subtraction angiogram image after injection of the right common carotid artery demonstrates a dilated and tortuous right occipital artery (arrow) and a fistula at the torcular herophili (arrowhead), with early filling of the straight sinus, vein of Galen, and internal cerebral veins (H). 


\section{Section 2}

Bilateral thalamic lesions represent an exceptional radiologic finding, but are common to several neurologic disorders (vascular, neoplastic, infectious, inflammatory, Creutzfeldt-Jakob disease, vitamin deficiency, osmotic myelinolysis, toxic insults, congenital disorders). ${ }^{1}$ Knowledge of the typical differential diagnosis is essential in order to recognize emergency situations such as top of the basilar artery occlusion, Percheron artery occlusion, and deep cerebral venous thrombosis. Considering the subacute onset and the progressive course of symptoms, together with the normality of noninvasive vessel imaging (CTA, magnetic resonance angiography $[\mathrm{MRA}]$ ), we ruled out vascular etiology. In the hypothesis of an inflammatory or infective process (such as West Nile encephalitis ${ }^{2}$ ), our next step was to perform a lumbar puncture. CSF was sterile with elevated proteins $(81 \mathrm{mg} / \mathrm{dL})$, normal cell count, and normal glucose. PCR of neurotropic viruses (including herpes simplex virus [HSV]-1, HSV-2, varicella-zoster virus, cytomegalovirus, Epstein-Barr virus, human herpesvirus 6, and enterovirus) and the West Nile virus was negative. The prion protein, onconeural antibodies, and antinuclear and extractable nuclear antigen antibodies were negative. In the hypothesis of Wernicke encephalopathy, the patient underwent 2 weeks of supplementation therapy with thiamine, $\mathrm{B}_{12}$, and folate, although serum levels were within normal range. No clinical improvement was appreciated. At this point, we considered neoplastic etiology, such as bithalamic glioma, thus a spectroscopy study and a subsequent possible biopsy were planned. Brain MRI was repeated and confirmed the previous bithalamic and midbrain abnormalities (figure, $\mathrm{A}$ and $\mathrm{B}$ ), but gradientecho sequences showed the presence of a new onset microhemorrhage in the right thalamus (figure, C). After a few days, the patient suddenly worsened into a coma. Urgent brain CT scan showed an acute intraparenchymal right thalamic hemorrhage, likely the evolution of the microbleed revealed by the MRI. This finding led us to reconsider a possible missed diagnosis of cerebrovascular disease, such as a vascular malformation or deep cerebral venous thrombosis. Thus, on the same day, we promptly decided to perform a cerebral angiography, the gold standard in the study of cerebral vasculature. Angiography revealed a Borden-Shucart type II (Cognard type IIA + B) dural arteriovenous fistula (dAVF) located at the torcular herophili with arterial supply from the branches of the right occipital artery and of the vertebral arteries (figure).

\section{Questions for Consideration:}

1. What is the pathophysiologic relationship between thalamic dementia, dAVF, bithalamic hyperintensities, and deep intracerebral hemorrhage?

2. What is the role of angiography?

GO TO SECTION 3 


\section{Section 3}

dAVFs consist of pathologic anastomoses between meningeal arteries and dural venous sinuses or cortical veins. ${ }^{3,4}$ Clinical manifestations are related to local hemodynamic changes induced by the shunt. Normal anterograde venous flow is reversed by high-pressure arterial flow through the shunt, resulting in retrograde flow in the venous sinus or cortical veins. In our patient, venous drainage occurred via retrograde flow through the straight sinus, vein of Galen, and internal cerebral veins. Blood flow reversal produced a deep vein congestion leading to venous hypertension with symptoms related to bithalamic venous ischemia. The involvement of the midbrain is explained by the common venous outflow: the basal veins (or veins of Rosenthal) run laterally to the midbrain and drain into the vein of Galen with the internal cerebral veins. ${ }^{5}$ The progressive increase in venous hypertension has likely led to the rupture of fragile arterialized veins causing a microbleed that evolved into the large thalamic hemorrhage.

Angiography is the gold standard for definitive dAVF diagnosis and is essential for treatment planning. Noninvasive imaging, such as MRA or CTA, can demonstrate an abnormality of cerebral vasculature, particularly enlarged or tortuous vessels, abnormal venous sinuses, early dural sinus opacification, and prominent draining veins. It is not always possible to visualize the fistula itself at the MRA/CTA because noninvasive imaging may have low diagnostic accuracy especially within deep cerebral veins. ${ }^{6}$ The dAVF was partially embolized using a transarterial approach, without a complete resolution. No improvement in neurologic status was appreciated after the treatment. A second embolization procedure was planned, but in the following days the patient worsened due to pneumonia and subsequent sepsis; he was admitted to the intensive care unit and died about 1 month later.

\section{Discussion}

dAVFs represent $10 \%-15 \%$ of all intracranial vascular malformations ${ }^{3}$ and differ by their arterial supply from vessels that perfuse the dura mater and by the lack of a parenchymal nidus. dAVFs are mainly idiopathic, but a small percentage of patients report a history of previous neurosurgery, infection, radiation exposure, pregnancy, trauma, or cerebral venous sinus thrombosis. Clinical presentation, such as focal deficits, encephalopathy, seizures, parkinsonism, ataxia, or dementia, depends on the location of the fistula. ${ }^{4}$ dAVFs are more frequently located in the region of the transverse and sigmoid sinus, the cavernous sinus, the superior sagittal sinus, and the tentorium.

dAVFs located at the tentorial edge, at the torcular erophili, or at the transverse-sigmoid junction, directly draining into the deep venous system and finally involving the vein of Galen and internal cerebral veins, can manifest themselves with symptoms of thalamic dementia, which is a less frequent presentation modality with a few dozen cases reported in the literature. $^{7-9}$ The mode of presentation is usually rapidly progressive (from weeks to a few months) and characterized by disorientation, hypersomnolence, executive dysfunction, attention deficit, and impaired memory, with additional neurologic deficits due to the involvement of nearby structures. The clinical course does not offer a diagnostic clue to a vascular etiology since these symptoms are shared by several disorders involving the thalamus bilaterally. Any clues may result from onset timing, associated symptoms, medical history, or other comorbidities.

Brain MRI shows, in all reported cases, bilateral thalamic T2/ FLAIR hyperintensities related to edema induced by venous congestion, in some cases with a patchy gadolinium enhancement and usually without diffusion restriction. Some signal alterations can also be appreciated in the nearby structures related to common venous outflow, such as the partial involvement of midbrain in our case. Although bilateral thalamic involvement is always demonstrated in dAVFinduced thalamic dementia, other disorders affecting the thalami can show similar radiologic features, ${ }^{1}$ making the differential diagnosis increasingly challenging.

As reported in a review ${ }^{9}$ of 19 cases of dAVF-induced thalamic dementia, the mean time of angiographic diagnosis is 87 days (range from 3 days to 18 months). In our case, the delay from onset of symptoms to the definitive diagnosis was 30 days. Although vascular etiology was one of our first hypotheses, the normality of vessel imaging, the progressive course, and the radiologic pattern have misled our attention to other possible etiologies than vascular ones. This kind of mistake may lead to unnecessary diagnostic tests with a consequent waste of time and potential harm caused by invasive procedures such as brain biopsy or lumbar puncture (a rapid severe neurologic decline has been described after lumbar puncture in cases of dAVF). Moreover, the risks associated with the administration of not indicated therapies and their potential adverse effects should be considered. The natural history of dAVFs depends on the type of the fistula. In the presence of cortical venous drainage or intracerebral hemorrhage, the prognosis is poor and timely treatment (endovascular, surgery, or combination) is recommended. As reported by Holekamp et al., ${ }^{9}$ dAVF-induced thalamic dementia uncomplicated by hemorrhage is associated with a high treatment success rate. Posttreatment MRI, when performed, reveals a noticeable improvement or complete resolution of pretreatment bithalamic hyperintensities. The long-term outcome is good with complete, or incomplete but significant, neurologic improvement. ${ }^{9}$

In the appropriate clinical setting, dAVF should always be considered in the differential diagnosis of bilateral thalamic hyperintensities and the suspicion for vascular etiology should increase if bleeding or microbleeds are found in the same or adjacent brain regions. 
Given the favorable prognosis of early treatment, cerebral angiography should be promptly performed even in the absence of vessel abnormalities in noninvasive imaging, considering the low diagnostic yield of these examinations in the deep cerebral venous system evaluation.

\section{Study Funding}

No targeted funding reported.

\section{Disclosure}

The authors report no disclosures relevant to the manuscript. Go to Neurology.org/N for full disclosures.

\begin{tabular}{lll}
\multicolumn{2}{l}{ Appendix } & Authors \\
\hline Name & Location & Contribution \\
\hline $\begin{array}{l}\text { Angelo } \\
\text { Cascio } \\
\text { Rizzo, MD }\end{array}$ & $\begin{array}{l}\text { Campus Bio-Medico } \\
\text { Italy }\end{array}$ & $\begin{array}{l}\text { Drafting the manuscript and the } \\
\text { figures }\end{array}$ \\
\hline $\begin{array}{l}\text { Novella } \\
\text { Bonaffini, } \\
\text { MD }\end{array}$ & $\begin{array}{l}\text { Sant'Eugenio } \\
\text { Hospital, Rome, }\end{array}$ & $\begin{array}{l}\text { Drafting the manuscript and } \\
\text { acquisition of data }\end{array}$ \\
\hline $\begin{array}{l}\text { Raffaele } \\
\text { Bove, MD }\end{array}$ & $\begin{array}{l}\text { Sant'Eugenio } \\
\text { Hospital, Rome, }\end{array}$ & $\begin{array}{l}\text { Revision of the manuscript and } \\
\text { acquisition of data }\end{array}$ \\
\hline $\begin{array}{l}\text { Italy } \\
\text { Gentile, }\end{array}$ & $\begin{array}{l}\text { Sant'Eugenio } \\
\text { Mospital, Rome, }\end{array}$ & Revision of the manuscript \\
\hline
\end{tabular}

Appendix (continued)

\begin{tabular}{lll}
\hline Name & Location & Contribution \\
\hline $\begin{array}{l}\text { Letizia } \\
\text { Maria } \\
\text { Cupini, MD }\end{array}$ & $\begin{array}{l}\text { Sant'Eugenio } \\
\text { Hospital, Rome, } \\
\text { Italy }\end{array}$ & Revision of the manuscript \\
\hline $\begin{array}{l}\text { Enrico } \\
\text { Cotroneo, } \\
\text { MD }\end{array}$ & $\begin{array}{l}\text { San Camillo } \\
\text { Hospital, Rome, } \\
\text { Italy }\end{array}$ & $\begin{array}{l}\text { MRI and angiography } \\
\text { interpretation and revision of the } \\
\text { figures; revision of the manuscript }\end{array}$ \\
$\begin{array}{l}\text { Cesare } \\
\text { Iani, MD }\end{array}$ & $\begin{array}{l}\text { Sant'Eugenio } \\
\text { Hospital, Rome, } \\
\text { Italy }\end{array}$ & Revision of the manuscript \\
& &
\end{tabular}

\section{References}

1. Linn J, Hoffmann LA, Danek A, Brückmann H. Differential diagnosis of bilateral thalamic lesions. Clin Neuroradiol 2007;179:234-245.

2. Guth JC, Futterer SA, Hijaz TA, et al, Pearls \& Oy-sters: bilateral thalamic involvement in West Nile virus encephalitis. Neurology 2014;83:e16-e17.

3. Reynolds MR, Lanzino G, Zipfel GJ. Intracranial dural arteriovenous fistulae. Stroke 2017;48:1424-1431.

4. Elhammady MS, Ambekar S, Heros RC, et al. Epidemiology, clinical presentation, diagnostic evaluation, and prognosis of cerebral dural arteriovenous fistulas. Handb Clin Neurol 2017;143:99-105.

5. Bordes S, Werner C, Mathkour M, et al. Arterial supply of the thalamus: a comprehensive review. World Neurosurg 2020;137:310-318.

6. Gandhi D, Chen J, Pearl M, Huang J, Gemmete GG, Kathuria S. Intracranial dural arteriovenous fistulas: classification, imaging findings, and treatment. Am J Neuroradiol 2012;33:1007-1013.

7. Parikh N, Merkler AE, Cheng NT, Baradaran H, White H, Leifer D. Clinical Reasoning: an unusual case of subacute encephalopathy. Neurology 2015;84:e33-e37.

8. Colorado RA, Matiello M, Yang HS, et al. Progressive neurological decline with deep bilateral imaging changes: a protean presentation of dural arteriovenous fistulae. Intervent Neurol 2018;7:256-264.

9. Holekamp TF, Mollman ME, Murphy RK, et al. Dural arteriovenous fistula-induced thalamic dementia: report of 4 cases. J Neurosurg 2016;124:1752-1765. 


\section{Neurology}

Clinical Reasoning: Rapidly Progressive Thalamic Dementia

Angelo Cascio Rizzo, Novella Bonaffini, Raffaele Bove, et al.

Neurology 2021;96;e809-e813 Published Online before print November 9, 2020

DOI 10.1212/WNL.0000000000011161

This information is current as of November 9, 2020

\section{Updated Information \&} Services

References

Subspecialty Collections

Permissions \& Licensing

Reprints including high resolution figures, can be found at: http://n.neurology.org/content/96/5/e809.full

This article cites 9 articles, 4 of which you can access for free at: http://n.neurology.org/content/96/5/e809.full\#ref-list-1

This article, along with others on similar topics, appears in the following collection(s):

All Cognitive Disorders/Dementia

http://n.neurology.org/cgi/collection/all_cognitive_disorders_dementia Arteriovenous malformation

http://n.neurology.org/cgi/collection/arteriovenous_malformation

Intracerebral hemorrhage

http://n.neurology.org/cgi/collection/intracerebral_hemorrhage

MRI

http://n.neurology.org/cgi/collection/mri

Information about reproducing this article in parts (figures,tables) or in its entirety can be found online at:

http://www.neurology.org/about/about_the_journal\#permissions

Information about ordering reprints can be found online:

http://n.neurology.org/subscribers/advertise

Neurology ${ }^{\circledR}$ is the official journal of the American Academy of Neurology. Published continuously since 1951, it is now a weekly with 48 issues per year. Copyright () 2020 American Academy of Neurology. All rights reserved. Print ISSN: 0028-3878. Online ISSN: 1526-632X.

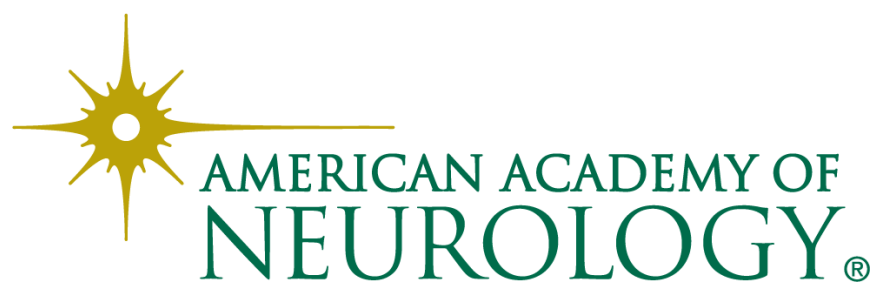

